NASA

Technical Memorandum 105805

\section{6 \\ $114 / 2 /$}

$P-22$ AVSCOM

Technical Report 92-C-024

\title{
A Simplified Dynamic Model of the T700 Turboshaft Engine
}

Ahmet Duyar and Zhen $\mathrm{Gu}$

Florida Atlantic University

Boca Raton, Florida

and

, Jonathan S. Litt

Propulsion Directorate

U.S. Army Aviation Systems Command

Lewis Research Center

Cleveland, Ohio

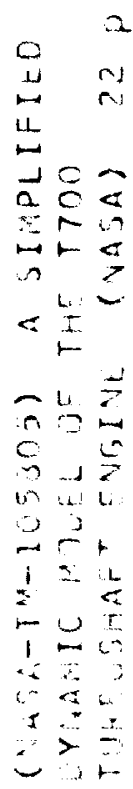

Prepared for the

48th American Helicopter Society Annual Forum sponsored by the American Helicopter Society

Washington, D.C., June 3-5, 1992 


\title{
A SIMPLIFIED DYNAMIC MODEL OF THE T700 TURBOSHAFT ENGINE ${ }^{1}$
}

\author{
Ahmet Duyar and Zhen Gu \\ Mechanical Engineering Department \\ Florida Atlantic University \\ Boca Raton, Florida 33431 \\ Jonathan S. Litt \\ Propulsion Directorate \\ U.S. Army Aviation Systems Command \\ Lewis Research Center \\ Cleveland, Ohio 44135
}

\begin{abstract}
A simplified open-loop dynamic model of the T700 turboshaft engine, valid within the normal operating range of the engine, is developed. This model is obtained by linking linear state space models obtained at different engine operating points. Each linear model is developed from a detailed nonlinear engine simulation using a multivariable system identification and realization method. The simplified model may be used with a model-based real time diagnostic scheme for fault detection and diagnostics, as well as for open loop engine dynamics studies and closed loop control analysis utilizing a user generated control law.
\end{abstract}

\section{Nomenclature}

Variables

$\begin{array}{ll}A, B, C, D, E, F, G, K, Z & \text { state space matrices } \\ \mathrm{N}_{8} & \text { gas generator speed } \\ \mathrm{N}_{M R} & \text { main rotor speed } \\ \mathrm{N}_{\mathrm{P}} & \text { power turbine speed } \\ \mathrm{P}_{S 3} & \text { static pressure at station 3 } \\ \mathrm{Q}_{\mathrm{R}} & \text { required torque } \\ \mathrm{Q}_{S} & \text { engine shaft torque } \\ \mathrm{T}_{45} & \text { interturbine gas temperature } \\ \mathbf{u} & \text { engine model input vector } \\ \mathrm{W}_{F} & \text { fuel flow } \\ \mathbf{X} & \text { engine model state vector } \\ \mathrm{XCPC} & \text { collective pitch } \\ \mathrm{y} & \text { engine model output vector }\end{array}$

Greek symbols $\delta[$ variable]

$\mu$

normalized deviation of variable from nominal observability index

\section{Subscript}

m

model

'This work was supported by the U.S. Army under grant number NAG3-1198. 


\section{Introduction}

Full nonlinear, component-based turbine engine simulations have, generally, been large, slow, unwieldy computer programs which require large amounts of computing power and time to produce small amounts of data. Due to their size and complexity, however, these nonlinear simulations are difficult to use for various control design and diagnostics studies. In this paper, a simplified state space model of the T700 engine is developed which can be used for control system design and model-based fault detection and diagnostics studies. This simplified model is developed using the data generated from a component-based real-time simulation of a T700 turboshaft engine which is described in [1].

Customarily, the development of simplified real-time turbine engine simulations involves creating piecewise linear state space perturbation models [2] at several operating points, enough to cover the operating range of interest. The set of linear systems covering the operating range is linked, sometimes using a curve-fitting technique, so that the resulting equation contains matrices whose elements are described by polynomials evaluated at the current operating point. This methodology was used in [3], [4], and [5].

In this paper, the procedure used to develop a simplified dynamic model of the T700 turboshaft engine is described. This approach was successfully applied to obtain simplified models for control and diagnostics design in other propulsion systems, for example [6]. Linearized dynamic models of the engine at five different operating conditions were obtained by using a multivariable system identification and realization technique [7] with the input and output data generated from the nonlinear simulation described in [1]. The simplified model, covering the whole range of operation of the engine, was then developed by combining the point models. The accuracy of the simplified model was checked by comparing the responses of certain engine variables to the corresponding responses from the nonlinear simulation for an input signal which drove the simplified model through a range of operating points.

A possible application of this model is a model-based diagnostics scheme for fault detection purposes which compares the parameters of the simplified model with the identified parameters of the actual system on a continuous basis. The differences between the modeled and identified parameters may be analyzed to detect the presence, to isolate the source, and to determine the extent of faults. Other applications for this model would include open loop engine dynamics studies, and closed loop control analysis with a user-generated control law.

The next section of this paper contains a description of the T700 engine. This is followed by sections describing the modeling and the identification of the open loop dynamics of the engine. Next, results obtained from the identified linear operating point models are compared with the results obtained from the nonlinear simulation for the same input. Finally, simulated output from the simplified model is compared with the results obtained from the nonlinear simulation for a given test input.

\section{Description of the T700-GE-700 Engine in a Helicopter Application}

The T700-GE-700 is a turboshaft engine used in pairs in the Army's Apache and Blackhawk helicopters. This 1600 horsepower-class, modular, two-spool engine (figure 1) consists of a gas generator section and a free power turbine [8]. The gas generator section is made up of a five-stage axial and a single-stage centrifugal compressor, a low fuel pressure flowthrough annular combustion chamber, and an air-cooled, two-stage, axial-flow, high-pressure turbine. The free power turbine is a two-stage, uncooled, axial-flow type. There exists a one-way coupling between the power turbine and the gas generator, i.e. the power turbine extracts work from the gas turbine cycle but does not otherwise affect it. Through mechanical linkages and gears, the power turbine drives the rotor system of the helicopter such that the rotor angular velocities are directly proportional to power turbine speed. Thus, in the helicopter application, it seems natural to consider the power turbine as part of the rotor system, to which it is mechanically linked [9].

The helicopter pilot commands an altitude change by moving the collective stick which alters the collective pitch of the main rotor blades. A change in the blade pitch angle causes a change in load as lift is increased or decreased. 
The standard 7700 control system regulates power turbine speed with fuel flow to accommodate variations in the load. The power turbine shaft is designed to operate at a constant $20,900 \mathrm{rpm}$. Changes in this power turbine speed are induced by disturbances such as collective pitch changes, wind gusts, etc. As the engine reaches a steady state condition, the control system causes the power turbine speed to return to its design point. The operating point of the engine is defined by the gas generator speed as a percent of its design speed as in [10].

As seen in figure 2, the two engines work in tandem employing a torque-sharing arrangement to tum the rotor system. In each engine, the power turbine's shaft is connected to the main gearbox through a nose box (a small reducing gearbox which redirects the torque by 90 degrees) and a freewheeling clutch. The main rotor is driven by a shaft projecting from the gearbox. The clutch allows the turbine to drive the rotor system but not vice versa. The tail rotor is driven by a shaft extending from the transmission which is turned though a gear mechanism powered by the main rotor. Thus, it spins as long as the main rotor is spinning, even if the engine is disengaged. When the helicopter tries to climb, implying that torque must be increased, the control system increases the fuel flow to the engines. The rotor applies a load to the turbine as long as they are engaged. A command to descend causes the control system to reduce fuel flow, thereby reducing the torque applied to the rotor from the shaft. The rotor will spin freely along with the shaft, but will only be driven by the shaft when friction slows the rotor down. This leads to a situation where the load depends on the direction of motion of the helicopter. A command to climb causes a significant load and the associated excursions in the state variables. On the other hand, a command to descend causes a sudden drop in load because the rotor's inertia keeps it spinning at the desired velocity even though fuel flow is reduced, meaning shaft torque is decreased.

\section{Modeling of the Open Loop Dynamics of the Engine}

As mentioned earlier, it is reasonable to consider the power turbine to be part of the load rather than the engine because of the one-way coupling and the direct linkage between the power turbine and the rotor. Figure 3 shows a block diagram of the open-loop engine/rotor system.

The basic objective of the control system of the engine is to maintain a constant power turbine speed in the presence of load disturbances. This is accomplished by modulating the fuel flow rate and the variable compressor geometry. However, for the purposes of this study and consistent with the nonlinear simulation, the variable geometry is assumed to be scheduled open loop as a function of compressor inlet temperature and gas generator speed. Following [9] and [11], the rotor system is treated as a separate dynamical system with engine shaft torque, $Q_{s}$, as input and the main rotor speed, $\mathrm{N}_{\mathrm{MR}}$ as output as shown in figure 3 . The main rotor speed is assumed to be proportional to the turbine speed by a constant gear ratio since the shaft elements between the hub and the power turbine are nearly rigid [9].

In figure 3, the inputs to the engine are the power turbine speed, $\mathrm{N}_{\mathrm{p}}$, and the fuel flow rate, $\mathrm{W}_{\mathrm{F}}$. The outputs are the gas generator speed, $N_{\varepsilon}$, engine torque transmitted by the power turbine shaft, $Q_{s}$, compressor static discharge pressure, $P_{s 3}$, and power turbine inlet temperature, $T_{45}$ (figure 1). All variables are normalized by dividing them by their values at $100 \%$ design gas generator speed. The pressure and the temperature are included in the output since they are used by the control system. Power turbine speed is considered as an input to the engine in order to reference the engine shaft torque with respect to that speed and to take into account the frictional losses.

In this study, the identification and modeling of the open loop dynamics of the helicopter engine as described above is considered separately from the rotor system. Once the model of the engine is obtained it can be coupled with any desired rotor system and the performance of the combined engine/rotor system can be analyzed.

The nonlinear open loop dynamics of the T700 helicopter engine can be described by the nonlinear differential equations 


$$
\begin{gathered}
x(t)=f(x(t), u(t)) \\
y(t)=g(x(t))
\end{gathered}
$$

where $x, u$, and $y$ are the state, the control and the output vectors, respectively. Linearizing these equations about a nominal operating condition and discretizing yields

$$
\begin{gathered}
\delta x(k+1)=A \delta x(k)+B \delta u(k) \\
\delta y(k)=C \delta x(k)
\end{gathered}
$$

where $\delta \mathrm{x}, \delta \mathrm{u}$, and $\delta \mathrm{y}$ are the normalized deviations of the state, the input, and the output vectors about the nominal operating conditions defined as

$$
\delta x_{i}=\frac{\left(x_{i}-x_{00}\right)}{x_{r d}}, \delta y_{i}=\frac{\left(y_{i}-y_{0 i}\right)}{y_{r d}}, \delta u_{i}=\frac{\left(u_{i}-u_{0 i}\right)}{u_{r d}}
$$

where the subscripts $i, n$ and 0 refers to the $i^{\text {th }}$ component, the normalization value and the nominal operating conditions. The normalization values and the nominal operating condition values are given in Table 1 .

It is assumed that the system described by equations (3) and (4) is stable and observable and the C matrix has full row rank. Furthermore, this system is realized in $\alpha$-canonical form developed in [7] and [12], i.e., the following
relations hold:

$$
\left.\begin{array}{c}
C=\left[0: H^{-1}\right] \\
A=A_{o}+K H C, \text { with } A_{o}^{\mu}=0 \\
(H C)_{r_{1}} A_{o}^{\mu_{1}}=0 \\
(H C)_{r_{t}} A_{o}^{k} K_{c_{1}}=0, \text { for } \mu_{i}>\mu_{j} \text { and } k<\mu_{i}-\mu_{j}
\end{array}\right\}
$$

Here the subscripts $r_{1}$ and $c_{j}$ denote the $i^{\text {th }}$ row and $j^{\text {th }}$ column respectively. Superscripts indicate exponentiation. The structure matrix $A_{0}$ is lower left triangular and consists of zeros and ones only and is determined by the observability indices, $\mu_{i}$, where $i$ associates $\mu_{i}$ with the $i^{\text {th }}$ output and $\mu=\max \left(\mu_{i}\right)$ [13]. The matrix $K$ is a deadbeat observer gain [14]. A procedure for obtaining a state transformation matrix to represent a linear system in $\alpha$-canonical form is presented in the appendix together with an example.

\section{System Identification Using the $\alpha$-Canonical Form}

System identification is defined [15] as the determination, on the basis of input and output, of a system within a specified class of systems, to which the system under test is equivalent. In this study, the specified class of systems considered for point models around nominal operating conditions is the class of linear systems described by equations (3) and (4).

Selection of an appropriate input signal to generate the output data is an important step in identification problems. A basic criterion for this selection is that the imput/output data should be informative enough to discriminate between different models among the class of models being considered [16]. Without this discrimination there is no guarantee that the obtained parameters are the true parameters of the system. This criterion can be expressed mathematically 
in terms of the covariance matrices of the input signals and the order of the system being identified [16]. Pseudorandom multi-level sequences, such as those used in this study, are examples of input signals that can be used for designing an informative experiment.

Once a class of systems and the input signal is selected, the identification problem becomes one of determining the A, B, C matrices of the system and its structure. To accomplish this, a multivariable system identification technique developed in [7] based on the $\alpha$-canonical form is used. This technique is briefly explained below for completeness.

The expression for the state $\delta x(k)$ at time $k$ of the system described by equations (3) through (6) is given by

$$
\delta x(k)=A_{o}^{k} \delta x(0)+\sum_{i=1}^{\mu} A_{o}^{i-1}[K: B]\left[\begin{array}{l}
\delta y(k-i) \\
\delta u(k-i)
\end{array}\right]
$$

Using the nilpotency of $A_{o}$ the above equation yields

$$
\delta x(k)=\sum_{i=1}^{\mu} A_{o}^{i-1}[K: B]\left[\begin{array}{l}
\delta y(k-i) \\
\delta u(k-i)
\end{array}\right], \text { for } k \geq \mu
$$

This implies that

$$
\delta y(k)=\sum_{i=1}^{\mu} C A_{o}^{i-1}[K: B]\left[\begin{array}{l}
\delta y(k-i) \\
\delta u(k-i)
\end{array}\right], \text { for } k \geq \mu
$$

The observability indices, $\mu_{\mathrm{i}}$, are evaluated from the observability matrix constructed from the input and output data as explained in [7]. If the observability index, $\mu$, is known, then equation (9) contains the unknown A, B and C matrices for given inputs and outputs. Using a data length of $\mathrm{N}$ and a least squares estimation technique, equation (9) can be solved for the unknown parameters.

\section{Linearized Point Models of the T700 Engine}

Using the above modeling and identification procedure, the parameters of the linear point models are estimated at five different operating points corresponding to different percentages of gas generator design speed levels as shown in table 1 . At each operating point, $\mu$ was found to be equal to 2 . As mentioned earlier, the input vector, $\delta u$, represents the normalized deviations of the power turbine speed and the fuel flow rate from the nominal values (table 1) defined as

$$
\delta u=\left[\begin{array}{ll}
\delta N_{p} & \delta W_{F}
\end{array}\right]^{T}
$$

The output vector, $\delta y$, represents the normalized deviations of the gas generator speed, engine shaft torque, interturbine gas temperature, and the compressor exit static pressure from their nominal values. It is defined as

$$
\delta y=\left[\begin{array}{llll}
\delta N_{s} & \delta Q_{s} & \delta T_{43} & \delta P_{s 3}
\end{array}\right]^{T}
$$

The validity of the estimated parameters of the system is checked by comparing the responses obtained from the identified system with the response of the nonlinear simulation. The model of the identified system utilizes the measurement of the input data, $\delta \mathrm{u}$, to predict the output, $\delta \mathrm{y}_{\mathrm{m}}$, and the state, $\delta \mathrm{x}_{\mathrm{m}}$, as 


$$
\begin{gathered}
\delta x_{m}(k+1)=A \delta x_{m}(k)+B \delta u(k) \\
\delta y_{m}(k)=C \delta x_{m}(k)
\end{gathered}
$$

A tri-level pseudo-random sequence is used for the fuel flow input. Since the power turbine speed input is basically used as a reference speed for engine shaft torque, a signal consisting of steps and ramps which cover he possible range of power turbine speed is used for that input. Both of the input signals are shown in figure 4 .

Most of the interaction between the rotor, drive train, and engine takes place at or below the main rotor frequency of about $300 \mathrm{rmm}(5 \mathrm{~Hz})$. Thus it is important that the simulation be accurate in the range below $5 \mathrm{~Hz}$. Based on a priori knowledge about the maximum rise time of the engine, a clock time of 2 seconds and a length of 26 (the number of unique outputs of the pseudo-random generator) is used with the tri-level sequence. The sampling time is selected to be 0.1 second. This corresponds to a maximum frequency of $31.4 \mathrm{rad} / \mathrm{sec}(5 \mathrm{~Hz})$, a minimum frequency of $0.12 \mathrm{rad} / \mathrm{sec}(0.02 \mathrm{~Hz})$ and a signal duration of $52 \mathrm{sec}$.

The test input signal consists of a full length tri-level pseudo-random sequence covering the same frequency range as the one used for identification as shown in figure 5 . In order to compare the responses of the identified system with the responses obtained from the nonlinear simulation, a standard error of estimate (SEE) is defined as

$$
S E E=\sqrt{\frac{\sum_{k=1}^{N}\left[\delta y_{m i}(k)-\delta y_{i}(k)\right]^{2}}{\sum_{k=1}^{N} \delta y_{i}^{2}(k)}}
$$

Here the subscript $i$ denotes the $i^{\text {th }}$ element of the output vector $\delta y$, and $\delta y_{m}$ refers to the model output. The SEE's obtained for the test signal, given in table 2, indicate very good agreement. Comparison of the responses of the identified model to the responses obtained from the nonlinear simulation for the input signals shown in figure 5 at an operating condition corresponding to $96 \%$ gas generator design speed are shown in figures 6 through 9 . The tests were done using the open loop nonlinear and linear point models of the T700. The figures show how closely the linear point model matches the nonlinear simulation for perturbations about an operating point. These figures are representative of the responses obtained at all operating points.

\section{A Simplified Model of the T700 Helicopter Engine}

A simplified model of the $T 700$ helicopter engine is obtained by linking the linear point models described above through look-up tables in a computer program. In this scheme, the gas generator speed is checked after each time step and the A, B and C matrices corresponding to the current operating conditions are used.

The computer program uses the actual (not normalized) values of the inputs and the outputs rather than the normalized deviations. Hence the five point models used are defined as

$$
\begin{gathered}
x(k+1)=D x(k)+E u(k)+F \\
y(k)=G x(k)+Z
\end{gathered}
$$

The values of these matrices for each of the operating conditions are given in table 3 . The order of the system model at each operating point, 8, equals the sum of the state variables times their corresponding observability index
at that operating point. 
The linked model was tested for accuracy across a range of operating points by comparing its response with that of the nonlinear simulation under simulated load conditions. A simple model representing the dynamometer described in [1], is used as the simulated load. The load is variable, based on a simulated collective pitch input, XCPC. The equations defining the load from [1] are

$$
\begin{gathered}
N_{P}=C_{1} \int\left(Q_{S}-Q_{R}\right) d t \\
Q_{R}=C_{2}\left(C_{3}-X C P C\left(C_{4}-C_{3} X C P C\right)\right) N_{P}^{2}
\end{gathered}
$$

where $Q_{s}$ and $Q_{R}$ are the engine shaft torque and the required torque. The values of the constants are: $C_{1}=0.534753$ $1 /\left(\mathrm{lb}-\mathrm{ft}-\mathrm{sec}^{2}\right), \mathrm{C}_{2}=1.86 \times 10^{-7} \mathrm{lb}-\mathrm{ft}-\mathrm{sec}^{2}, \mathrm{C}_{3}=75.0, \mathrm{C}_{4}=0.1047$, and $\mathrm{C}_{5}=0.1085$.

To test the validity of the simplified model, the profile of the collective pitch input, XCPC, shown in figure 10 was used as input to the dynamometer model (equations (17) and (18)). Beginning with the initial conditions of the engine and XCPC, the dynamometer model and closed loop nonlinear simulation were numerically integrated simultaneously to produce the responses represented by solid lines in figures 12-16. The values of fuel flow rate, $\mathrm{W}_{\mathrm{F}}$ (figure 11), obtained from the control system portion of the nonlinear simulation, and power turbine speed, $\mathrm{N}_{\mathrm{P}}$ (figure 12), obtained from the nonlinear simulation, were then used as input to the simplified model. Figure 12 shows the comparison of the $\mathrm{N}_{\mathrm{p}}$ values obtained directly from the nonlinear model and from the simplified model determined by using the torque output, $\mathrm{Q}_{s}$, in the dynamometer model (equations (17) and (18)). As shown in figures 13-16, the simplified model passes through several operating regions (as defined by $\mathrm{N}_{\mathrm{g}}$ (figure 13)) and the variables match those of the nonlinear simulation closely.

\section{Conclusions}

A multivariable system identification technique is used to obtain point models of the T700 helicopter engine from data generated by a nonlinear simulation. These point models are used to obtain a simplified model of the engine. The validity of the simplified model is checked by comparing the response of the nonlinear simulation with the response obtained from the simplified model under simulated load conditions. The comparison indicates good agreement between these responses. Therefore it has potential to be used with a model-based real time fault detection and diagnostics design, as well as for open loop engine dynamics studies. Because it is in state space form, the model is convenient for closed loop control analysis utilizing a user generated control law.

\section{Appendix: The $\alpha$-Canonical Form}

Consider a linear, time-invariant system with an irreducible realization given as

$$
\begin{aligned}
q(k+1) & =D q(k)+E u(k) \\
y(k) & =F q(k)
\end{aligned}
$$

with observability indices $\mu_{i}$, where $i$ associates $\mu_{i}$ with the $i^{\text {th }}$ output. Here the state vector, $q$, the input vector, $u$, and the output vector, $\mathrm{y}$, are $\mathrm{nx} 1, \mathrm{mxl}$, and $\mathrm{px} 1$ respectively. A state transformation $\mathrm{T}$ can be used to represent this system in $\alpha$-canonical form as

$$
A=T D T^{-1}, \quad B=T E, \quad C=F T^{-1},
$$

where the $A$ and $C$ matrices satisfy (6). The state transformation matrix $T$ is obtained by using a reduced observability matrix, $\mathrm{V}$., which is obtained from the observability matrix, $\mathrm{V}$, after deleting all rows which are linearly dependent on the previous ones. The matrix $\mathrm{T}$ is defined [12] as 


$$
\begin{gathered}
T \Delta\left[\begin{array}{c}
(H F)_{*, \mu}\left(D-K_{1} F\right)^{\mu-1} \\
(H F)_{*, \mu-1}\left(D-K_{1} F\right)^{\mu-2} \\
\cdot \\
\cdot \\
(H F)_{*, 1}
\end{array}\right] \\
K_{1} \Delta D H_{1} \\
H_{1} \Delta\left[D^{\mu_{1}-1} d_{1} D^{\mu_{2}-1} d_{2} \ldots . D^{\mu,-1} d_{p}\right] \\
H \Delta\left(F H_{1}\right)^{-1}
\end{gathered}
$$

where $(\mathrm{HF})_{*,}$ is the matrix obtained from HF after deleting the rows with associated observability indices $\mu_{t}<\mathrm{t}$. The column vectors, $d_{1}$ denote those columns of $V_{t^{-1}}$ such that

$$
F_{r_{i}} D^{\mu_{i}-1} d_{i}=1
$$

where the subscript $r_{i}$ denotes the $i^{\text {th }}$ row. The deadbeat observer gain, $K$, for the transformed system of (6) is obtained from that of the untransformed system, $K_{1}$, by

$$
K=T K_{1} \text {. }
$$

Example: Let $(\mathrm{D}, \mathrm{E}, \mathrm{F})$ be an irreducible system with the realization

$$
D=\left[\begin{array}{ccc}
0 & 1 & 0 \\
k_{1} & k_{2} & k_{3} \\
k_{4} & k_{5} & k_{6}
\end{array}\right], \quad E=\left[\begin{array}{l}
e_{1} \\
e_{2} \\
e_{3}
\end{array}\right], \quad F=\left[\begin{array}{lll}
1 & 0 & 0 \\
0 & 0 & 1
\end{array}\right]
$$

where, from $V$, the observability indices are $\mu_{1}=2$ and $\mu_{2}=1$. For this system, the observability matrix, $V$, the reduced observability matrix, $V_{.}$, and the vectors $d_{1}$ and $d_{2}$ are obtained as

$$
\begin{gathered}
V=\left[\begin{array}{ccc}
1 & 0 & 0 \\
0 & 0 & 1 \\
0 & 1 & 0 \\
k_{4} & k_{5} & k_{6} \\
k_{1} & k_{2} & k_{3} \\
k_{1} k_{5}+k_{4} k_{6} & k_{4}+k_{2} k_{5}+k_{5} k_{6} & k_{3} k_{5}+k_{6}^{2}
\end{array}\right], \quad V_{*}=V_{*}^{-1}=\left[\begin{array}{lll}
1 & 0 & 0 \\
0 & 0 & 1 \\
0 & 1 & 0
\end{array}\right], \\
d_{1}=\left[\begin{array}{l}
0 \\
1 \\
0
\end{array}\right], \quad d_{2}=\left[\begin{array}{l}
0 \\
0 \\
1
\end{array}\right] .
\end{gathered}
$$

Hence $H, K_{1}$ and $H_{1}$ can be evaluated as 


$$
H_{1}=\left[\begin{array}{ll}
1 & 0 \\
k_{2} & 0 \\
k_{5} & 1
\end{array}\right], K_{1}=\left[\begin{array}{cc}
k_{2} & 0 \\
k_{1}+k_{2}^{2}+k_{3} k_{5} & k_{3} \\
k_{4}+k_{2} k_{5}+k_{5} k_{6} & k_{6}
\end{array}\right], H=\left[\begin{array}{cc}
1 & 0 \\
-k_{5} & 1
\end{array}\right]
$$

noting that

$$
(H F)_{.2}=\left[\begin{array}{lll}
1 & 0 & 0
\end{array}\right],(H F)_{*, 1}=\left[\begin{array}{ccc}
1 & 0 & 0 \\
-k_{3} & 0 & 1
\end{array}\right]
$$

The transformation matrix $\mathrm{T}$ can be determined as

$$
T=\left[\begin{array}{ccc}
-k_{2} & 1 & 0 \\
1 & 0 & 0 \\
-k_{5} & 0 & 1
\end{array}\right]
$$

Using the state transformation yields $A, B$, and $C$ matrices as well as $A_{o}$ using (6) and $K$ as

$$
\begin{gathered}
A=\left[\begin{array}{ccc}
0 & k_{1}+k_{3} k_{5} & k_{3} \\
1 & k_{2} & 0 \\
0 & k_{4}+k_{5} k_{6} & k_{6}
\end{array}\right], B=\left[\begin{array}{c}
e_{2}-k_{2} e_{1} \\
e_{1} \\
e_{3}-k_{5} e_{1}
\end{array}\right], C=\left[\begin{array}{lll}
0 & 1 & 0 \\
0 & k_{3} & 1
\end{array}\right] \\
A_{0}=\left[\begin{array}{lll}
0 & 0 & 0 \\
1 & 0 & 0 \\
0 & 0 & 0
\end{array}\right], K=\left[\begin{array}{cc}
k_{1}+k_{3} k_{5} & k_{3} \\
k_{2} & 0 \\
k_{4}+k_{5} k_{6} & k_{6}
\end{array}\right] .
\end{gathered}
$$

\section{Acknowledgements}

The authors sincerely wish to thank the following people for sharing their expertise in the areas of turboshaft engines, helicopter transmissions, turboshaft engine simulations, and data collection: George Bobula, Pete Meitner, and Mark Valco of the Army Aviation Systems Command Propulsion Directorate; Dan Gilmore of GE; Mark Ballin and Michelle Eshow of NASA Ames; and Dr. Bruce Lehtinen and Dr. Ten-Huei Guo of the NASA Lewis Advanced Control Technology Branch.

\section{References}

1. Ballin, M. G., "A High Fidelity Real-Time Simulation of a Small Turboshaft Engine," NASA TM 100991, July, 1988.

2. Mihaloew, J. R., Roth, S. P., "A Piecewise Linear State Variable Technique for Real Time Propulsion System Simulation," Thirteenth Annual Pittsburgh Conference on Modelling and Simulation, Pittsburgh, PA, April 22-23, 1982.

3. Merrill, W. C., Beattie, E. C., LaPrad, R. F., Rock, S. M., Akhter, M. M., "HYTESS-A Hypothetical Turbofan Engine Simplified Simulation," NASA TM 83561, January, 1984. 
4. Litt, J. S., DeLaat, J. C., Merrill, W. C., "A Real-time Simulator of a Turbofan Engine," NASA TM 100869, March 1989.

5. Duyar, A., Eldem, V., Merrill, W. C., Guo, T. -H., "A Simplified Dynamic Model of the Space Shuttle Main Engine," Proceedings of the 1991 American Control Conference, June 26-28, 1991, Boston, MA.

6. Guo, T. -H., Duyar, A., Merrill, W. C., "A Distributed Failure Diagnosis and Detection System Using On-line Parameter Estimation," Proceedings of the IFAC International Symposium on Distributed Intelligent Systems," Arlington, VA, August 13-15, 1991, pp. 248-253.

7. Duyar, A., Eldem, V., Merrill, W. C., Guo, T. -H., "State Space Representation of the Open Loop Dynamics of the Space Shuttle Main Engine," ASME Journal of Dynamic Systems Measurement and Control, Vol. 113, pp. 684690.

8. Prescott, W. E., Morris, H. F., "T700 Training Guide," SEI-418, General Electric Company, Aircraft Engine Business Group, Lynn, MA, 1987.

9. Pfeil, W. H., de los Reyes, G., Bobula, G. A., "The Application of LQR Synthesis Techniques to the Turboshaft Engine Control Program," AIAA-84-1455, 20th Joint Propulsion Conference, Cincinnati, OH, June 11-13, 1984.

10. Pfeil, W. H., Athans, M., Spang, H. A., III, "Multi-variable Control of the GE T700 Engine using the LQG/LTR Design Methodology," Proceedings of the 1986 American Control Conference, Seattle, WA, June 18-20, 1986.

11. Minto, K. D., "Towards Simultaneous Performance: Application of Simultaneous Stabilization Techniques to Helicopter Engine Control," Proceedings of the 1988 American Control Conference, Atlanta, GA, June 15-17, 1988.

12. Eldem, V, Yildizbayrak, N., "Parameter and Structure Identification of Linear Multivariable Systems," Automatica, 24, pp. 365-373.

13. Chen, C. -T., Linear System Theory and Design, Holt, Rinehart and Winston, 1984.

14. Kwakernaak, H., Sivan, R., Linear Optimal Control Systems, Wiley-Interscience, 1972.

15. Zadeh, L. A., "From Circuit Theory to System Theory," Proc. IRE, 50, pp. 856-865.

16. Ljung, L., System Identification: Theory for the User," Prentice-Hall, 1987. 
Table 1. Operating Points and Normalization Values Used for Model Development

\begin{tabular}{|c|c|c|c|c|c|c|}
\hline \multicolumn{2}{|c|}{ operating point: 1} & 2 & 3 & 4 & 5 & normalization \\
\hline$\% \mathrm{~N}_{\mathrm{p}}(\%)$ & 100.0 & 100.0 & 100.0 & 100.0 & 100.0 & 100.0 \\
\hline $\mathrm{W}_{\mathrm{F}}(\mathrm{lb} / \mathrm{sec})$ & 0.0884 & 0.1170 & 0.1456 & 0.1742 & 0.2028 & 0.217 \\
\hline$\% \mathrm{~N}_{\mathrm{g}}(\%)$ & 87.5 & 91.4 & 94.5 & 96.7 & 98.5 & 99.5 \\
\hline$Q_{s}(f t-1 b)$ & 9369. & 15309. & 21443 . & 27303. & 32619. & 35150. \\
\hline $\mathrm{T}_{45}(\operatorname{deg} \mathrm{R})$ & 1472. & 1578. & 1675. & 1778. & 1896. & 1954. \\
\hline$P_{s 3}(p s i)$ & 132.0 & 161.7 & 188.9 & 212.3 & 231.5 & 240.5 \\
\hline \multicolumn{4}{|c|}{ Gas generator design speed $=44,700 \mathrm{rpm}$} & \multicolumn{3}{|c|}{ Power turbine design speed $=20,900 \mathrm{rpm}$} \\
\hline
\end{tabular}

Table 2. Standard Error of Estimate (SEE) for each Point Model

\begin{tabular}{llllll}
\hline \hline operating point: 1 & 2 & 3 & 4 & 5 \\
\hline & & & & & \\
$\mathrm{N}_{\mathrm{g}}$ & 0.0428 & 0.0368 & 0.0615 & 0.0488 & 0.0458 \\
$\mathrm{Q}_{\mathbf{s}}$ & 0.0746 & 0.0519 & 0.0578 & 0.0578 & 0.0568 \\
$\mathrm{~T}_{45}$ & 0.0556 & 0.0236 & 0.0350 & 0.0258 & 0.0238 \\
$\mathrm{P}_{\mathrm{s3}}$ & 0.0597 & 0.0403 & 0.0440 & 0.0444 & 0.0441 \\
\hline
\end{tabular}

Table 3. State Space Matrices at each Operating Point

\begin{tabular}{|c|c|c|c|c|c|c|c|c|c|c|c|}
\hline \multirow{3}{*}{$\begin{array}{c}\text { Operating } \\
\text { Point } \\
1\end{array}$} & \multicolumn{8}{|c|}{$\mathrm{D}_{1}$} & \multicolumn{2}{|c|}{$E_{1}$} & $F_{1}$ \\
\hline & 0.0000 & 0.0000 & 0.0000 & 0.0000 & -0.5693 & 0.0007 & 0.0029 & -0.0007 & 0.0000 & -0.3489 & 0.0290 \\
\hline & 0.0000 & 0.0000 & 0.0000 & 0.0000 & -0.1112 & -0.0251 & 0.0340 & -0.1119 & 0.0039 & -1.7818 & -0.2349 \\
\hline \multirow[t]{10}{*}{$\% \mathrm{~N}_{\mathrm{g}}=87$} & 0.0000 & 0.0000 & 0.0000 & 0.0000 & 0.0060 & -0.0110 & -0.0156 & 0.0769 & -0.0001 & -1.9504 & 0.1833 \\
\hline & $\begin{array}{l}0.0000 \\
1.0000\end{array}$ & $\begin{array}{l}0.0000 \\
0.0000\end{array}$ & 0.0000 & 0.0000 & -0.2870 & -0.0045 & 0.0265 & -0.1018 & -0.0001 & -1.1076 & 0.1074 \\
\hline & 0.0000 & $\begin{array}{l}0.0000 \\
1.0000\end{array}$ & 0.0000 & 0.0000 & 1.5083 & 0.0052 & 0.0244 & 0.0152 & 0.0000 & $\left|\begin{array}{l}0.3906 \\
1.6791\end{array}\right|$ & $\begin{array}{r}-0.0355 \\
0.2350\end{array}$ \\
\hline & 0.0000 & $\begin{array}{l}1.0000 \\
0.0000\end{array}$ & 0.0000 & 0.0000 & 0.0540 & 1.0484 & 0.1716 & 0.0699 & -0.0038 & $\mid \begin{array}{l}1.6791 \\
2.2966\end{array}$ & -0.2097 \\
\hline & 0.0000 & $\begin{array}{l}0.0000 \\
0.0000\end{array}$ & $\begin{array}{l}1.0000 \\
0.0000\end{array}$ & $\begin{array}{l}0.0000 \\
1.0000\end{array}$ & $\begin{array}{l}0.0513 \\
0.2935\end{array}$ & $\begin{array}{r}-0.0035 \\
0.0377\end{array}$ & $\begin{array}{l}0.8414 \\
0.1450\end{array}$ & $\begin{array}{r}-0.1075 \\
10227\end{array}$ & $\begin{array}{l}0.0001 \\
0.0002\end{array}$ & $\begin{array}{l}2.2966 \\
0.9788\end{array}$ & -0.1086 \\
\hline & \multicolumn{8}{|c|}{$\mathrm{G}_{1} / 10,000$} & \multicolumn{3}{|c|}{$Z_{1} / 1000$} \\
\hline & 0.0000 & 0.0000 & 0.0000 & 0.0000 & 0.0050 & 0.0000 & 0.0000 & 0.0000 & \multirow{4}{*}{\multicolumn{3}{|c|}{$\begin{array}{l}0.0875 \\
9.3699 \\
1.4723 \\
0.1320\end{array}$}} \\
\hline & 0.0000 & 0.0000 & 0.0000 & 0.0000 & 0.0000 & 3.5150 & 0.0000 & 0.0000 & & & \\
\hline & 0.0000 & 0.0000 & 0.0000 & 0.0000 & 0.0000 & 0.0000 & 0.1954 & 0.0000 & & & \\
\hline & 0.0000 & 0.0000 & 0.0000 & 0.0000 & 0.0000 & 0.0000 & 0.0000 & 0.0241 & & & \\
\hline
\end{tabular}




\begin{tabular}{|c|c|c|c|c|c|c|c|c|c|c|c|}
\hline \multirow{2}{*}{$\begin{array}{c}\text { Operating } \\
\text { Point } \\
2\end{array}$} & \multicolumn{8}{|c|}{$D_{2}$} & \multicolumn{2}{|c|}{$\mathrm{E}_{2}$} & $F_{2}$ \\
\hline & 0.0000 & 0.0000 & 0.0000 & 0.0000 & -0.0854 & 0.0042 & 0.0303 & -0.2789 & $0.0003 \mid-1$ & -1.2022 & 0.1121 \\
\hline \multirow{12}{*}{$\% \mathrm{~N}_{\mathrm{B}}=91$} & 0.0000 & 0.0000 & 0.0000 & 0.0000 & -0.1431 & -0.0124 & 0.0263 & -0.2383 & $0.0054 \mid-1$ & -1.8996 & -0.3146 \\
\hline & 0.0000 & 0.0000 & 0.0000 & 0.0000 & 0.1316 & -0.0214 & -0.0030 & 0.0115 & $-0.0001 \mid-3$ & -3.4306 & 0.4131 \\
\hline & 0.0000 & 0.0000 & 0.0000 & 0.0000 & -0.0490 & 0.0054 & 0.0155 & -0.2032 & $-0.0001-1$ & -1.0120 & 0.1308 \\
\hline & 1.0000 & 0.0000 & 0.0000 & 0.0000 & 0.9005 & 0.0387 & 0.1179 & 0.3565 & 0.0000 & 1.1722 & -0.1333 \\
\hline & 0.0000 & 1.0000 & 0.0000 & 0.0000 & 0.2190 & 0.9875 & 0.0232 & 0.0826 & -0.0055 & 2.0429 & 0.3105 \\
\hline & 0.0000 & 0.0000 & 1.0000 & 0.0000 & -0.2122 & 0.0224 & 0.9004 & 0.1200 & 0.0001 & 3.7381 & -0.4496 \\
\hline & 0.0000 & 0.0000 & 0.0000 & 1.0000 & 0.0651 & 0.0027 & 0.0488 & 1.0918 & 0.0002 & 1.0806 & -0.1443 \\
\hline & \multicolumn{8}{|c|}{$\mathrm{G}_{2} / 10,000$} & \multicolumn{3}{|c|}{$\mathrm{Z}_{2} / 10,000$} \\
\hline & 0.0000 & 0.0000 & 0.0000 & 0.0000 & 0.0020 & 0.0000 & 0.0000 & 0.0000 & \multirow{4}{*}{\multicolumn{3}{|c|}{$\begin{array}{l}0.0091 \\
1.5309 \\
0.1578 \\
0.0162\end{array}$}} \\
\hline & 0.0000 & 0.0000 & 0.0000 & 0.0000 & 0.0000 & 3.5150 & 0.0000 & 0.0000 & & & \\
\hline & 0.0000 & 0.0000 & 0.0000 & 0.0000 & 0.0000 & 0.0000 & 0.0977 & 0.0000 & & & \\
\hline & 0.0000 & 0.0000 & 0.0000 & 0.0000 & 0.0000 & 0.0000 & 0.0000 & 0.0241 & & & \\
\hline \multirow{14}{*}{$\begin{array}{c}\text { Operating } \\
\text { Point } \\
3\end{array}$} & \multicolumn{8}{|c|}{$\mathrm{D}_{3}$} & \multicolumn{2}{|l|}{$\mathrm{E}_{3}$} & $F_{3}$ \\
\hline & 0.0000 & 0.0000 & 0.0000 & 0.0000 & -0.3647 & -0.0018 & -0.0299 & -0.0480 & $0.0001-1$ & -1.3495 & 0.1882 \\
\hline & 0.0000 & 0.0000 & 0.0000 & 0.0000 & -0.2227 & -0.0238 & -0.0234 & -0.2175 & $0.0067-1$ & -1.9331 & -0.3854 \\
\hline & 0.0000 & 0.0000 & 0.0000 & 0.0000 & 0.0683 & -0.0040 & 0.0111 & -0.0043 & $|-0.0004|-2$ & -2.6354 & 0.4276 \\
\hline & 0.0000 & 0.0000 & 0.0000 & 0.0000 & -0.0907 & -0.0030 & -0.0071 & -0.2529 & -0.0002 & -1.0774 & 0.1818 \\
\hline & 1.0000 & 0.0000 & 0.0000 & 0.0000 & 1.4046 & 0.0330 & 0.1345 & -0.1597 & 0.0002 & 1.4103 & -0.2208 \\
\hline & 0.0000 & 1.0000 & 0.0000 & 0.0000 & 0.3485 & 0.9633 & 0.0278 & 0.0699 & -0.0071 & 2.2315 & 0.3835 \\
\hline & 0.0000 & 0.0000 & 1.0000 & 0.0000 & $\mid-0.1249$ & -0.0291 & 0.8871 & 0.1523 & 0.0002 & 2.8748 & -0.4379 \\
\hline & 0.0000 & 0.0000 & 0.0000 & 1.0000 & 0.1720 & -0.0049 & 0.0422 & 1.0942 & 0.00021 & 1.2196 & -0.1984 \\
\hline & \multicolumn{8}{|c|}{$\mathrm{G}_{3} / 10,000$} & \multicolumn{3}{|c|}{$Z_{3} / 10,000$} \\
\hline & 0.0000 & 0.0000 & 0.0000 & 0.0000 & 0.0020 & 0.0000 & 0.0000 & 0.0000 & \multirow{4}{*}{\multicolumn{3}{|c|}{$\begin{array}{l}0.0095 \\
2.1443 \\
0.1675 \\
0.0189\end{array}$}} \\
\hline & 0.0000 & 0.0000 & 0.0000 & 0.0000 & 0.0000 & 3.5150 & 0.0000 & 0.0000 & & & \\
\hline & 0.0000 & 0.0000 & 0.0000 & 0.0000 & 0.0000 & 0.0000 & 0.0977 & 0.0000 & & & \\
\hline & 0.0000 & 0.0000 & 0.0000 & 0.0000 & 0.0000 & 0.0000 & 0.0000 & 0.0241 & & & \\
\hline Operating & \multicolumn{8}{|c|}{$\mathrm{D}_{4}$} & $\mathrm{E}_{4}$ & $E_{4}$ & $F_{4}$ \\
\hline 4 & 0.0000 & 0.0000 & 0.0000 & 0.0000 & -0.1189 & 0.0117 & -0.0555 & -0.2425 & $0.0002-1$ & -1.3652 & 0.2187 \\
\hline & 0.0000 & 0.0000 & 0.0000 & 0.0000 & -0.1117 & 0.0001 & -0.0694 & -0.2907 & $0.0082-2$ & -2.1470 & -0.4475 \\
\hline$\% \mathrm{~N}_{\mathrm{g}}=96$ & 0.0000 & 0.0000 & 0.0000 & 0.0000 & -0.1844 & -0.0053 & -0.0231 & 0.1612 & $-0.0004 \mid-2$ & -2.4216 & 0.4639 \\
\hline & 0.0000 & 0.0000 & 0.0000 & 0.0000 & 0.0141 & 0.0062 & -0.0314 & $|-0.2777|$ & -0.0003 & -1.1647 & 0.2341 \\
\hline & 1.0000 & 0.0000 & 0.0000 & 0.0000 & 1.2199 & 0.0296 & 0.1830 & -0.1058 & 0.0002 & 1.3654 & -0.2562 \\
\hline & 0.0000 & 1.0000 & 0.0000 & 0.0000 & 0.4792 & 0.9547 & 0.1041 & -0.1177 & $-0.0086 \mid$ & 2.2683 & 0.4652 \\
\hline & 0.0000 & 0.0000 & 1.0000 & 0.0000 & 0.1081 & -0.0554 & 0.8530 & 0.1633 & -0.0001 & 2.6815 & -0.4549 \\
\hline & 0.0000 & 0.0000 & 0.0000 & 1.0000 & 0.2352 & 0.0041 & 0.1156 & 0.8711 & 0.0004 & 1.1848 & -0.2478 \\
\hline & \multicolumn{8}{|c|}{$\mathrm{G}_{4} / 10,000$} & \multicolumn{3}{|c|}{$\mathrm{Z}_{4} / 10,000$} \\
\hline & 0.0000 & 0.0000 & 0.0000 & 0.0000 & 0.0020 & 0.0000 & 0.0000 & 0.0000 & \multirow{4}{*}{\multicolumn{3}{|c|}{$\begin{array}{l}0.0097 \\
2.7303 \\
0.1778 \\
0.0212\end{array}$}} \\
\hline & 0.0000 & 0.0000 & 0.0000 & 0.0000 & 0.0000 & 3.5150 & 0.0000 & 0.0000 & & & \\
\hline & 0.0000 & 0.0000 & 0.0000 & 0.0000 & 0.0000 & 0.0000 & 0.0977 & 0.0000 & & & \\
\hline & 0.0000 & 0.0000 & 0.0000 & 0.0000 & 0.0000 & 0.0000 & 0.0000 & 0.0241 & & & \\
\hline
\end{tabular}




\begin{tabular}{|c|c|c|c|c|c|c|c|c|c|c|c|}
\hline \multirow{3}{*}{$\begin{array}{l}\text { Operating } \\
\text { Point } \\
5\end{array}$} & \multicolumn{8}{|c|}{$D_{s}$} & \multicolumn{2}{|c|}{$E_{5}$} & $F_{3}$ \\
\hline & 0.0000 & 0.0000 & 0.0000 & 0.0000 & 0.1907 & 0.0070 & 0.0524 & -0.5436 & 0.0002 & -2.2727 & 0.4455 \\
\hline & 0.0000 & 0.0000 & 0.0000 & 0.0000 & 0.2123 & -0.0049 & 0.0805 & -0.5187 & 0.0099 & -1.8996 & -0.6058 \\
\hline \multirow{11}{*}{$\% \mathrm{~N}_{\mathrm{B}}=99$} & 0.0000 & 0.0000 & 0.0000 & 0.0000 & -0.0201 & 0.0044 & 0.0145 & -0.1358 & 0.0000 & -2.7338 & 0.5555 \\
\hline & 0.0000 & 0.0000 & 0.0000 & 0.0000 & 0.2010 & 0.0008 & 0.0765 & -0.4728 & -0.0007 & -1.7053 & 0.4108 \\
\hline & 1.0000 & 0.0000 & 0.0000 & 0.0000 & 0.8479 & 0.0651 & 0.4640 & -0.0258 & 0.0006 & 2.4826 & -0.5654 \\
\hline & 0.0000 & 1.0000 & 0.0000 & 0.0000 & -0.1461 & 0.9894 & 0.0142 & 0.3239 & -0.0101 & 2.1337 & 0.5726 \\
\hline & 0.0000 & 0.0000 & 1.0000 & 0.0000 & -0.0120 & -0.0284 & 0.8055 & 0.3132 & $-0.0002 \mid$ & 2.8933 & -0.5624 \\
\hline & 0.0000 & 0.0000 & 0.0000 & 1.0000 & -0.0855 & 0.0273 & 0.1515 & 1.0695 & 0.0010 & 1.9276 & -0.4874 \\
\hline & \multicolumn{8}{|c|}{$\mathrm{G}_{s} / 10,000$} & \multicolumn{3}{|c|}{$\mathrm{Z}_{\mathrm{y}} / 10,000$} \\
\hline & 0.0000 & 0.0000 & 0.0000 & 0.0000 & 0.0010 & 0.0000 & 0.0000 & 0.0000 & \multirow{4}{*}{\multicolumn{3}{|c|}{$\begin{array}{l}0.0098 \\
3.2619 \\
0.1896 \\
0.0232\end{array}$}} \\
\hline & 0.0000 & 0.0000 & 0.0000 & 0.0000 & 0.0000 & 1.7575 & 0.0000 & 0.0000 & & & \\
\hline & 0.0000 & 0.0000 & 0.0000 & 0.0000 & 0.0000 & 0.0000 & 0.0977 & 0.0000 & & & \\
\hline & 0.0000 & 0.0000 & 0.0000 & 0.0000 & 0.0000 & 0.0000 & 0.0000 & 0.0241 & & & \\
\hline
\end{tabular}

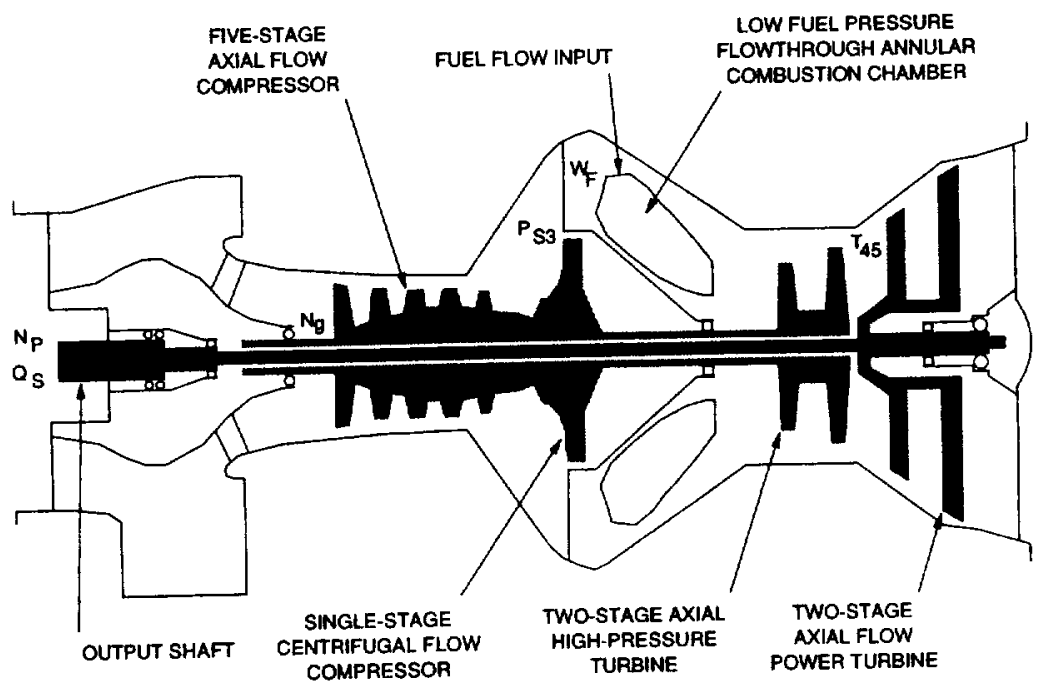

Figure 1.-Cross section of a T700 turboshaft engine. 


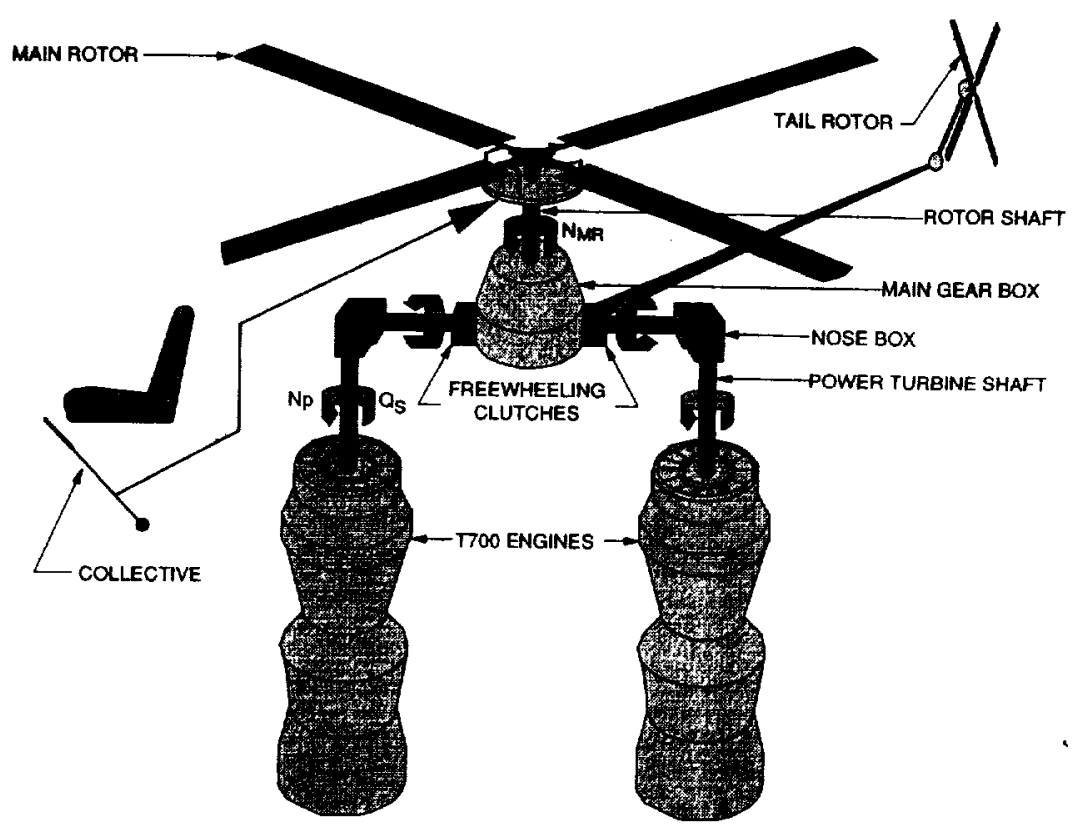

Figure 2.-Twin engine/rotor system in a helicopter.

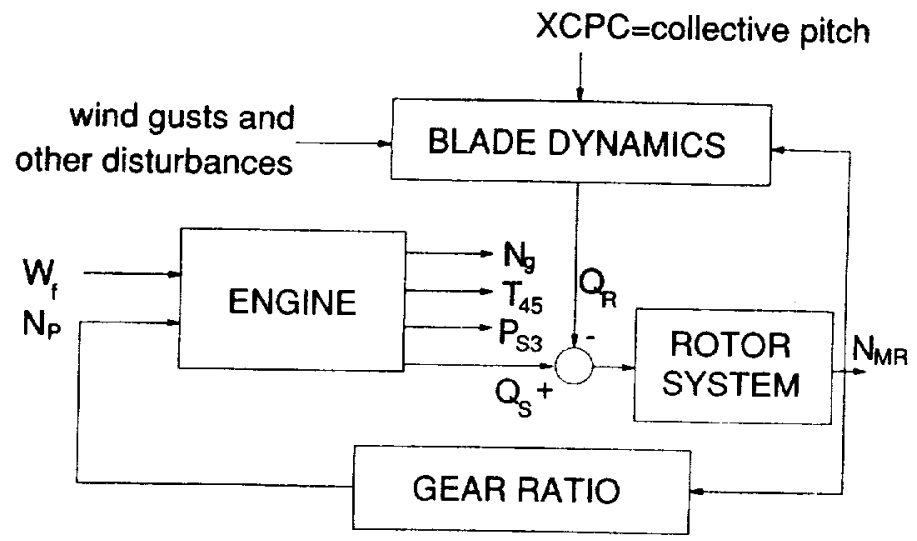

Figure 3.-Open-loop engine/rotor system. 


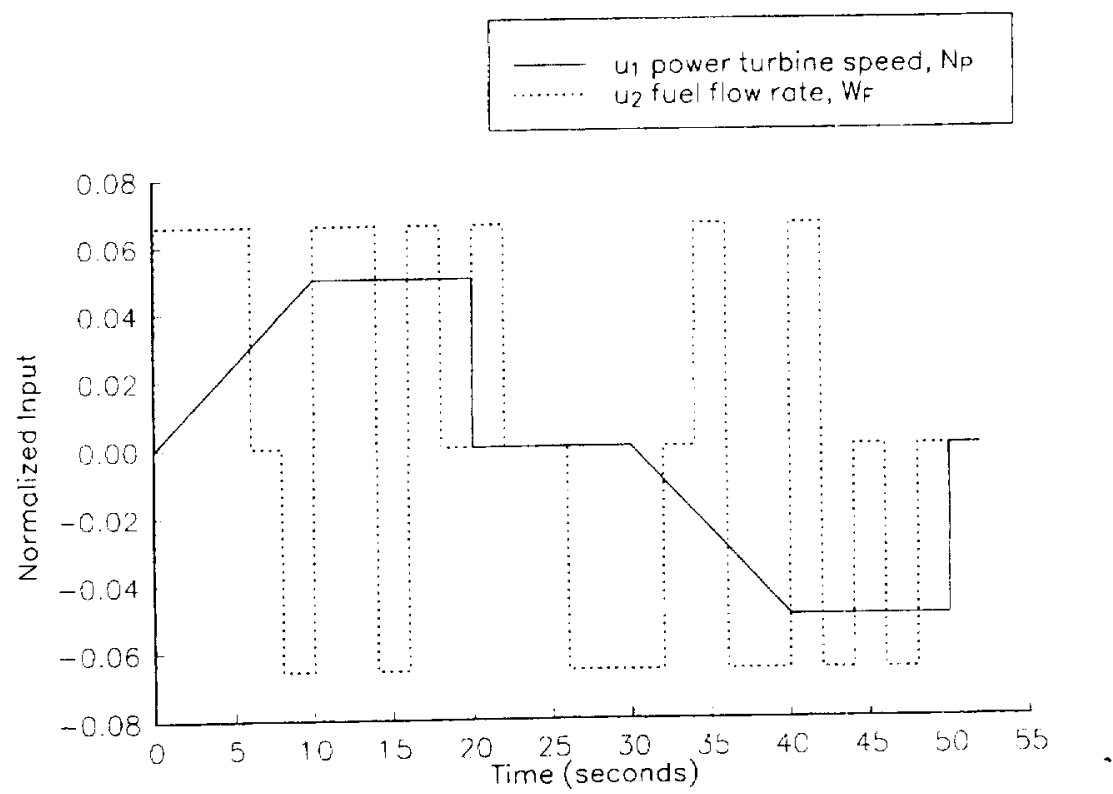

Figure 4.- Input signals $u_{1}\left(N_{p}\right)$ and $u_{2}\left(W_{F}\right)$.

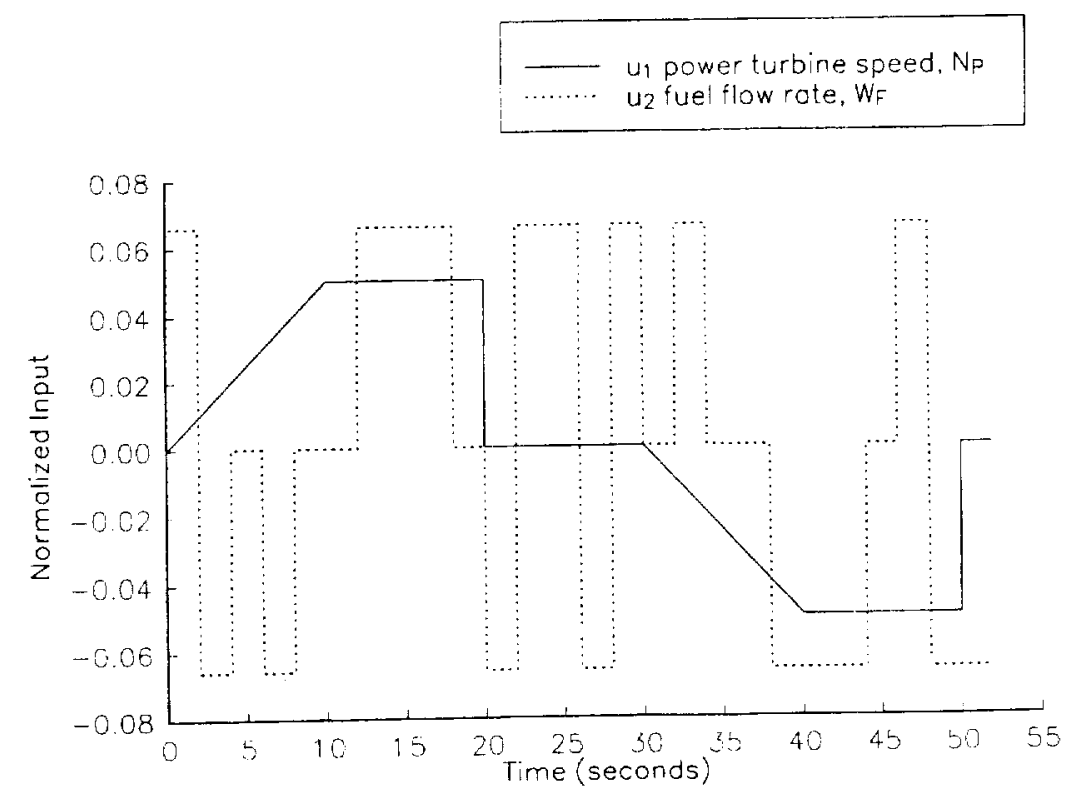

Figure 5.-Test input signals $u_{1}\left(N_{p}\right)$ and $u_{2}\left(W_{F}\right)$. 


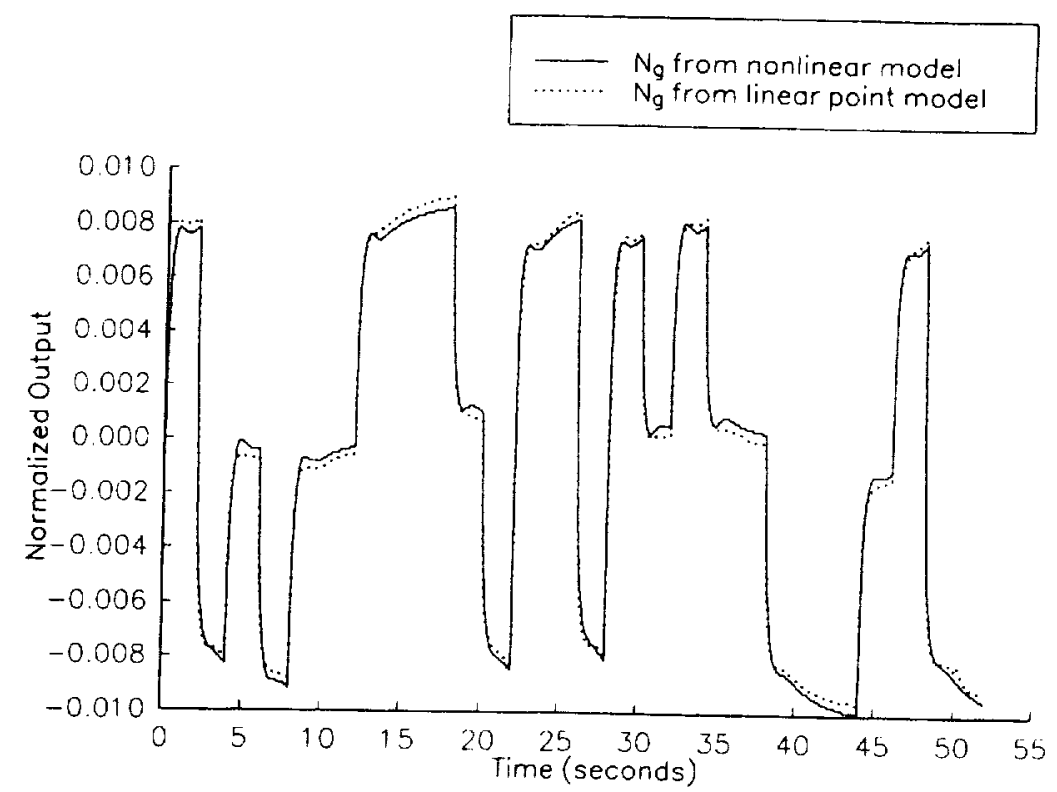

Figure 6.-Gas generator speed at 96 percent gas generator design speed.

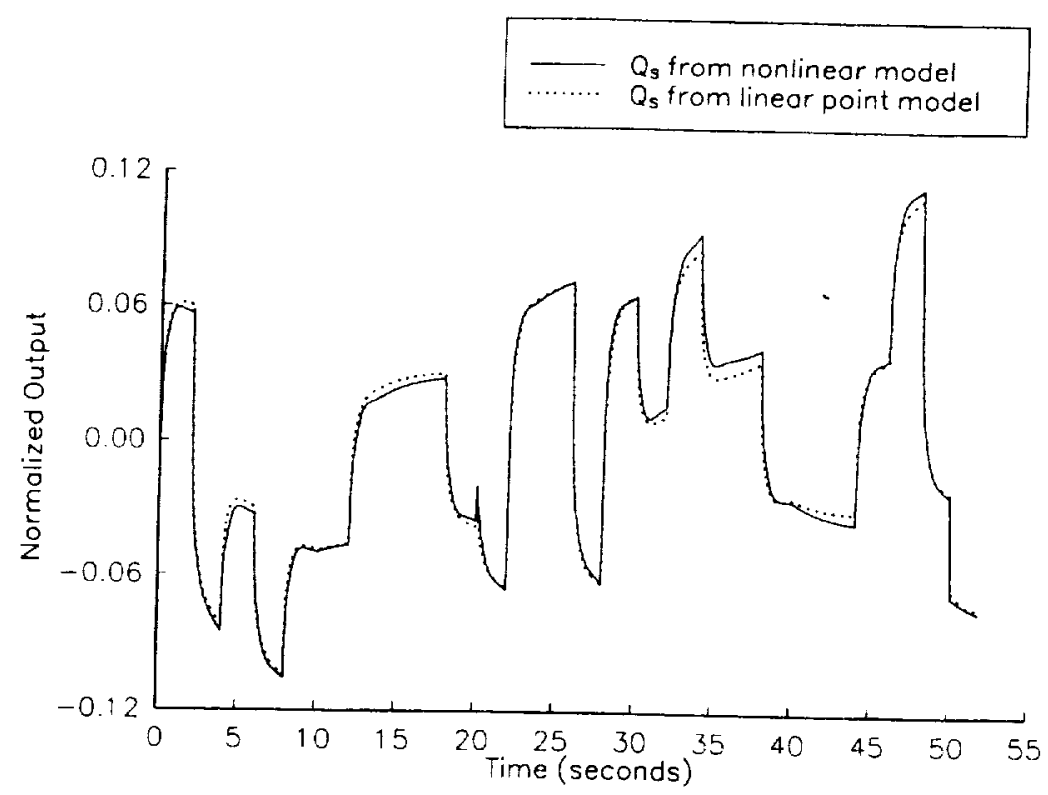

Figure 7.-Output torque at 96 percent gas generator design speed. 


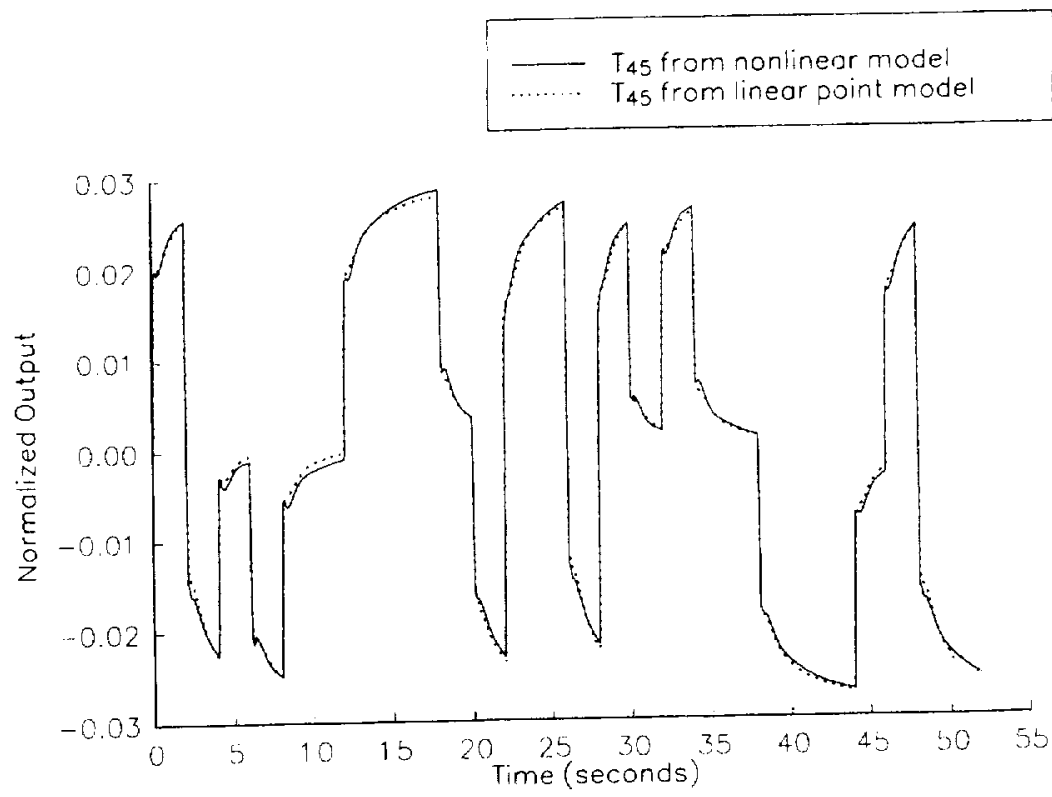

Figure 8.-Station 4.5 temperature at 96 percent gas generator design speed.

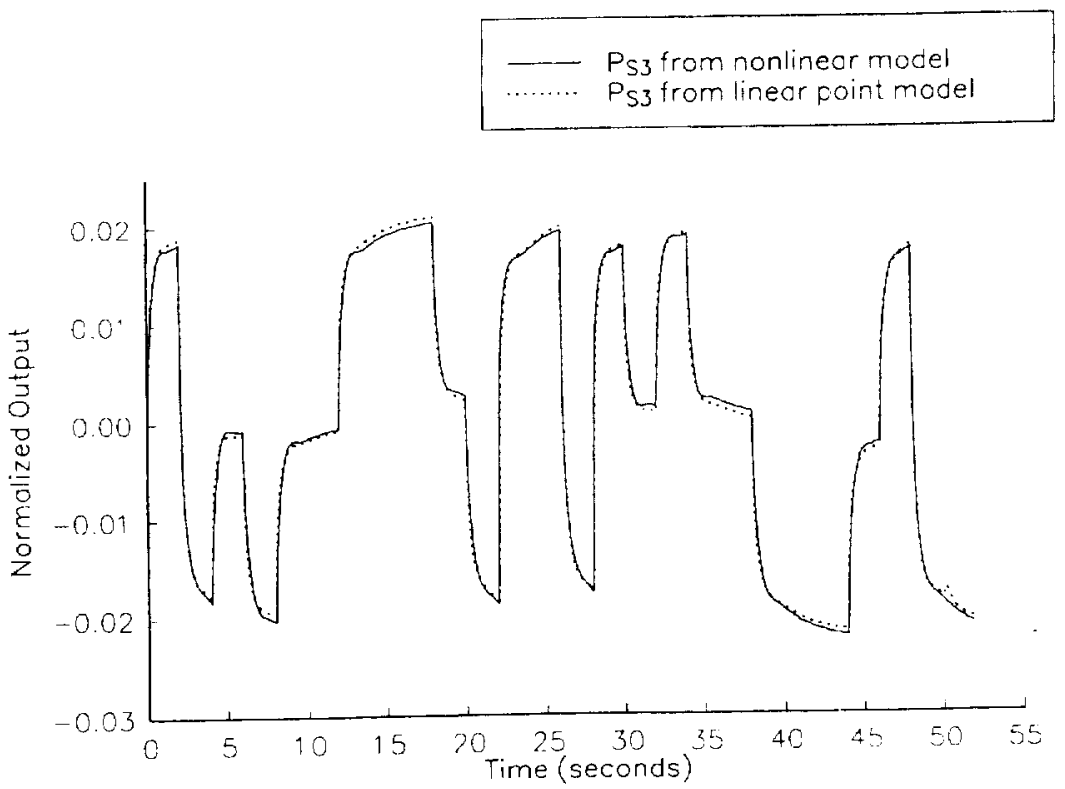

Figure 9.-Station 3 static pressure at 96 percent gas generator design speed. 


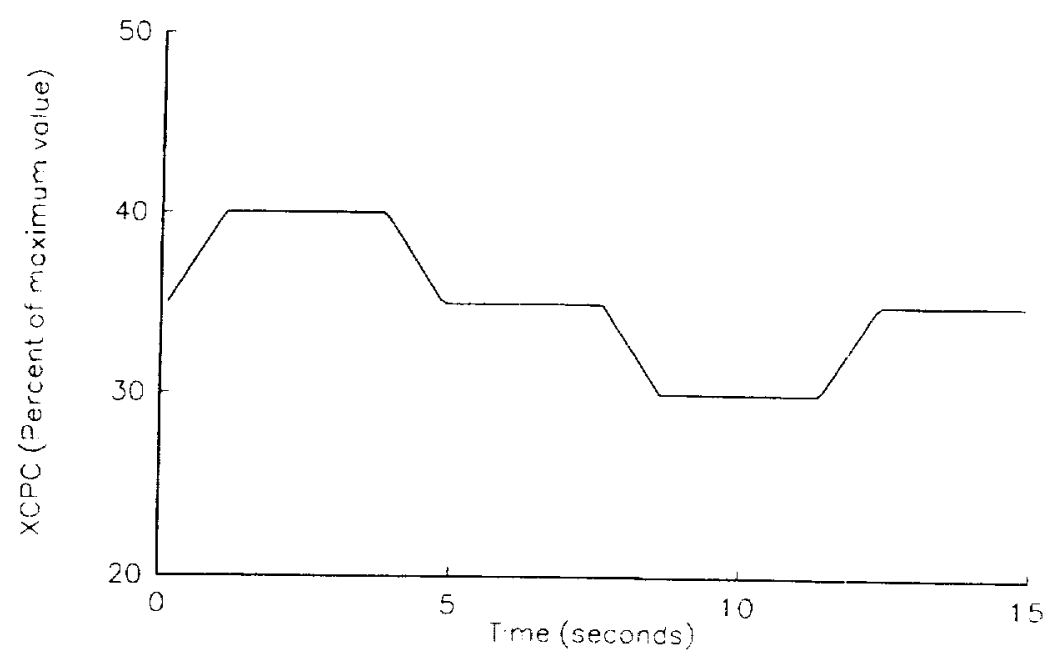

Figure 10.-Collective pitch input.

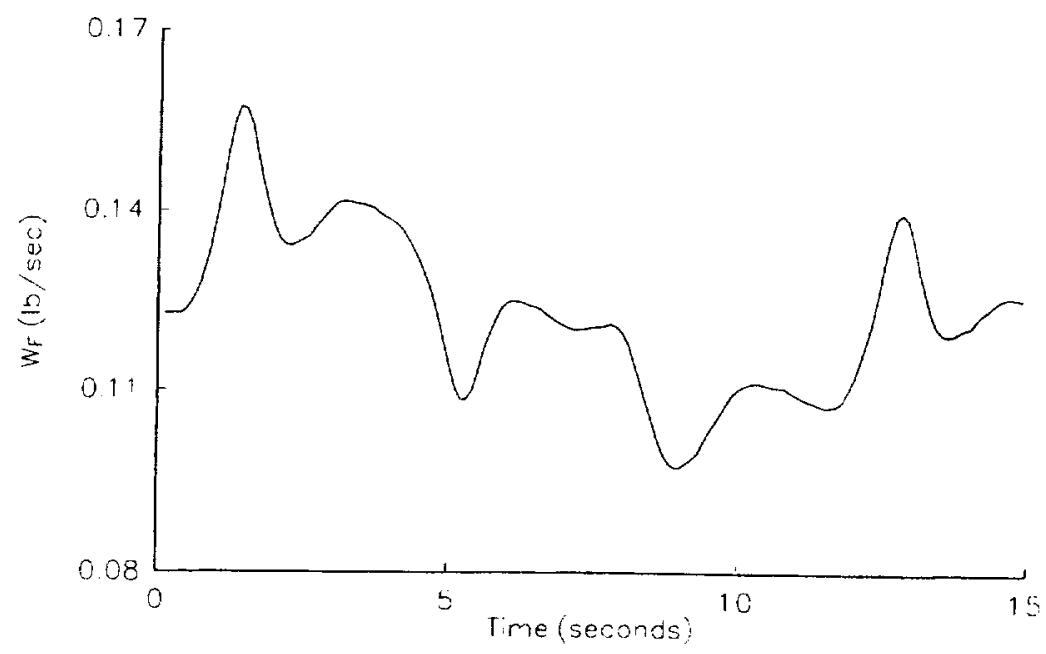

Figure 11.-Fuel flow rate.

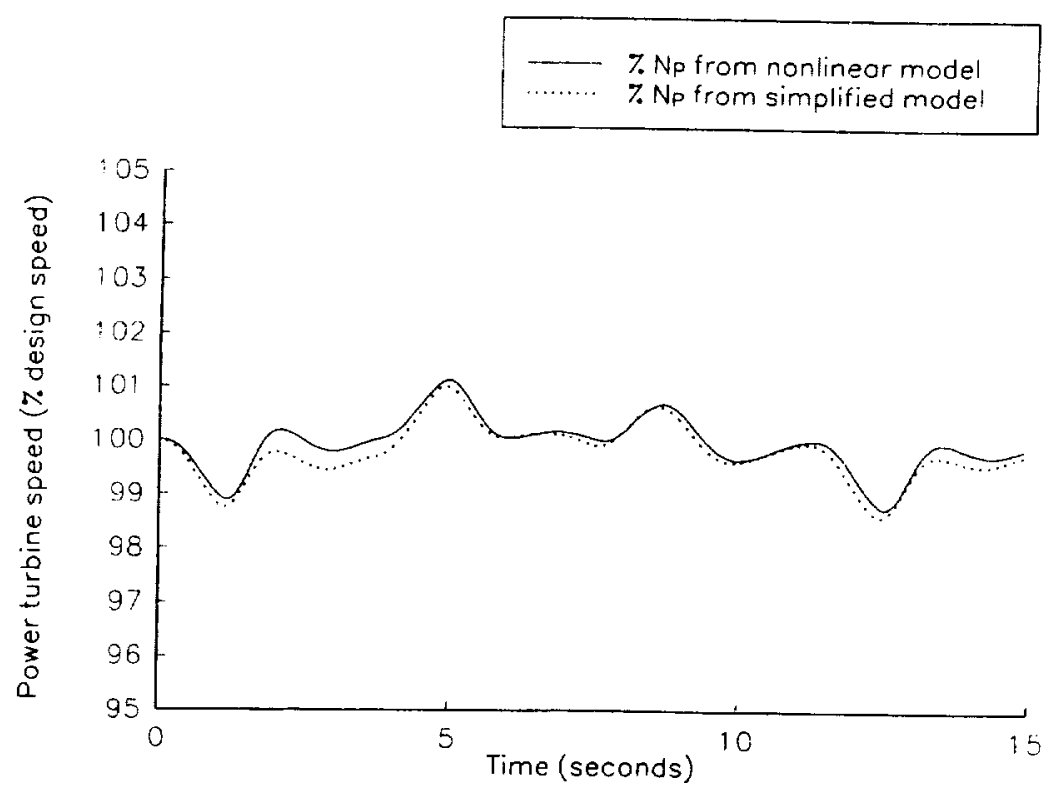

Figure 12.-Comparison of nonlinear model with simplified model. 


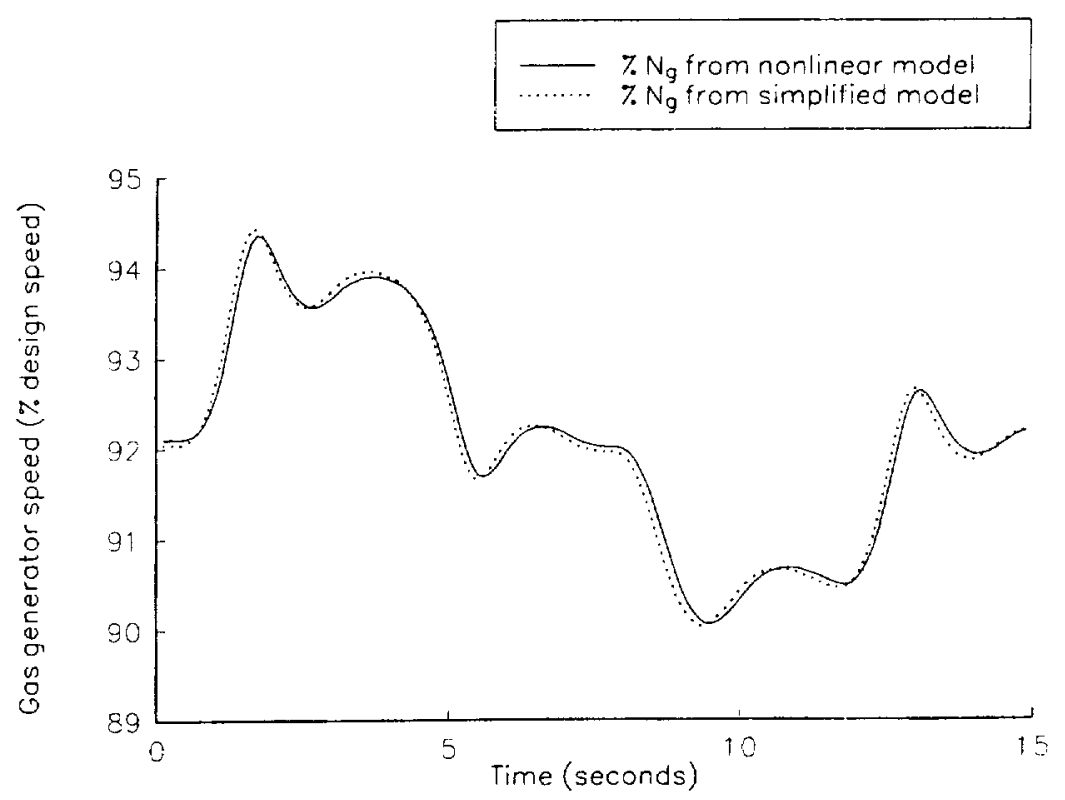

Figure 13.-Comparison of nonlinear model with simplified model.

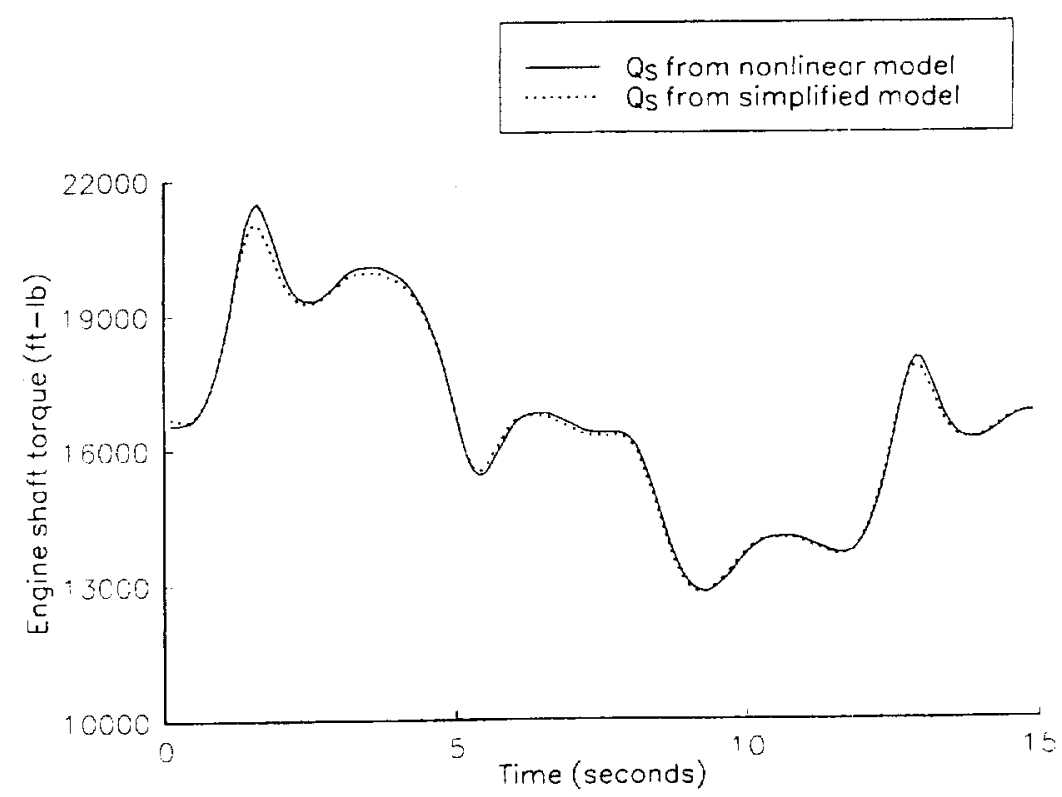

Figure 14.-Comparison of nonlinear model with simplified model. 


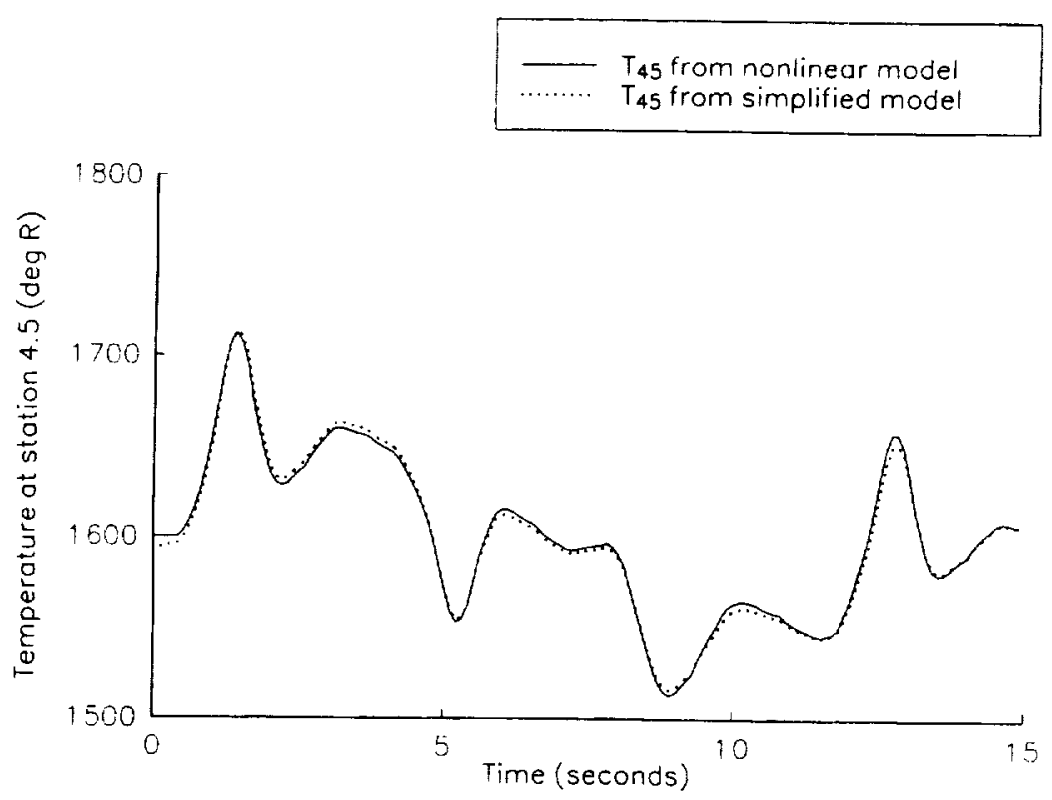

Figure 15.-Comparison of nonlinear model with simplified model.

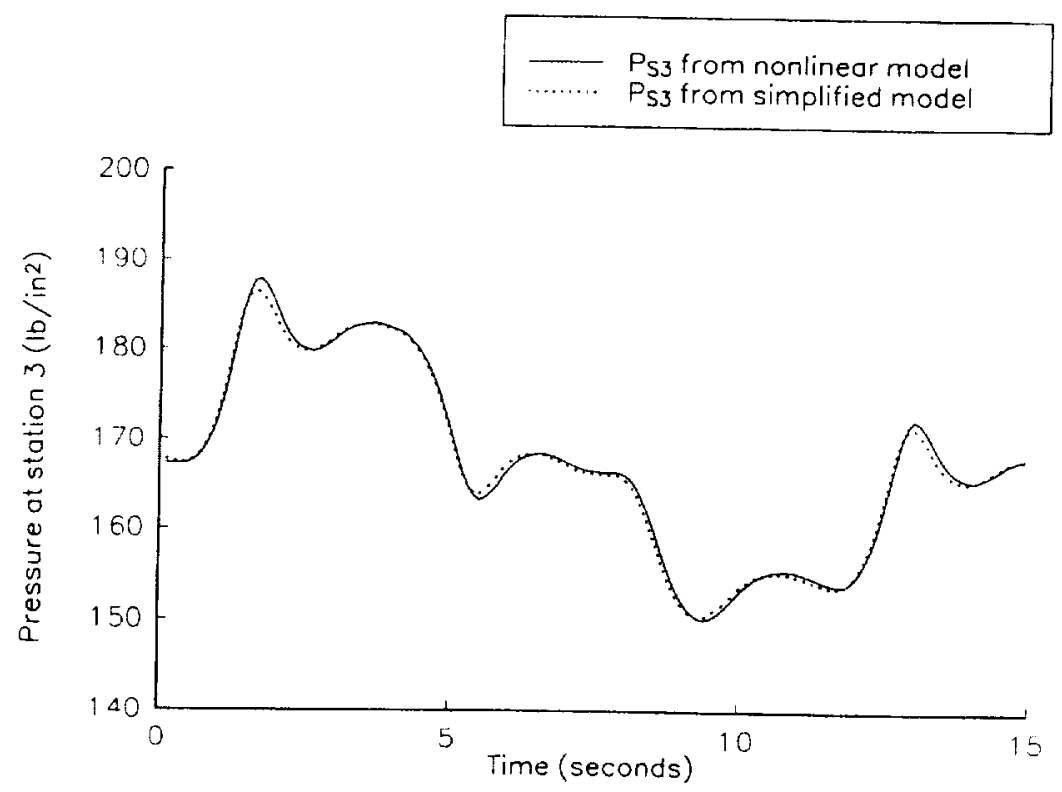

Figure 16.-Comparison of nonlinear model with simplified model. 



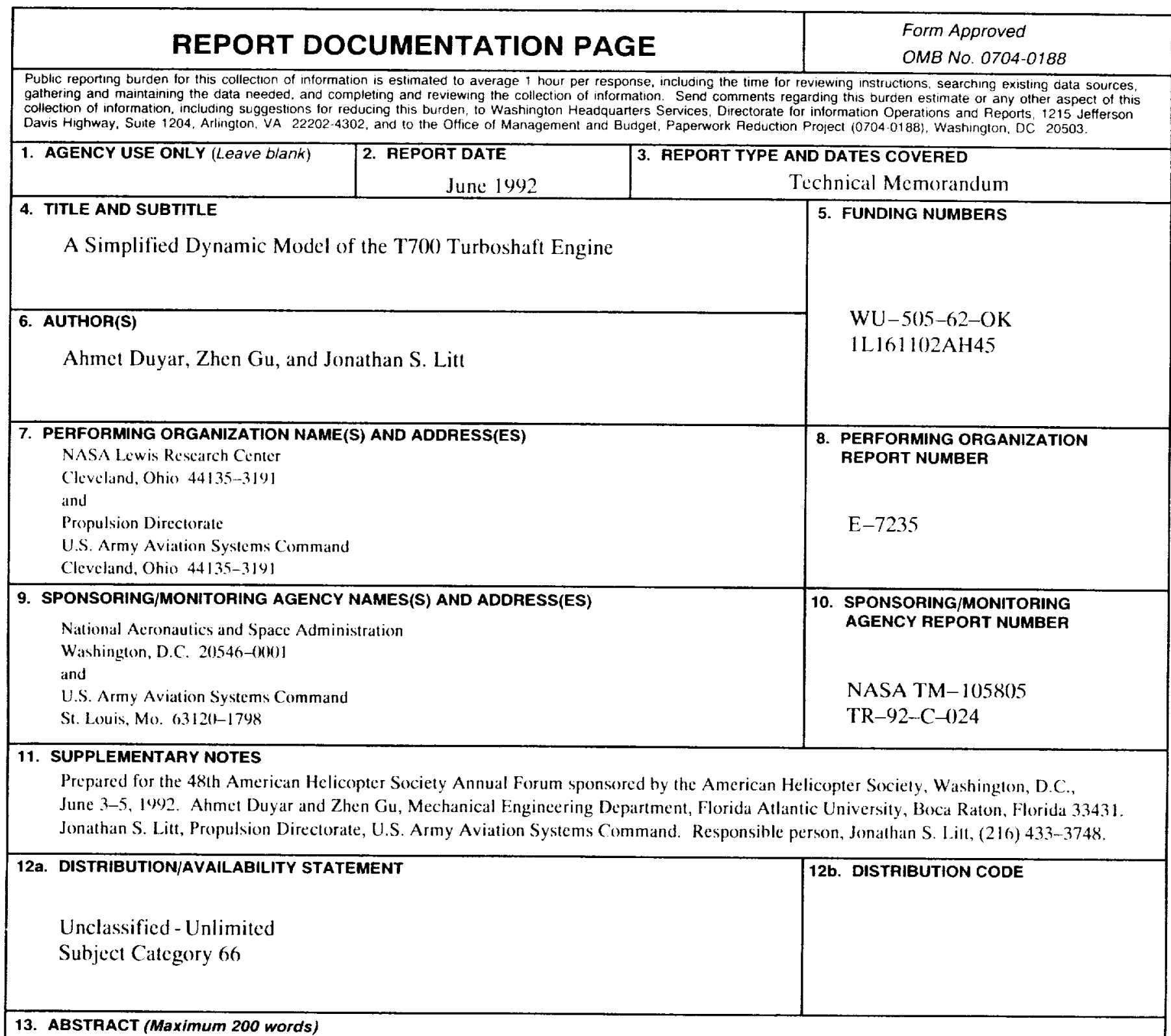

A simplified open-loop dynamic model of the T700 turboshaft engine, valid within the normal operating range of the engine, is developed. This model is obtained by linking linear state space models obtained at different engine operating points. Each linear model is developed from a detailed nonlinear engine simulation using a multivariable system identification and realization method. The simplified model may be used with a model-based real time diagnostic scheme for fault detection and diagnostics, as well as for open loop engine dynamics studies and closed loop control analysis utilizing a user generated control law.

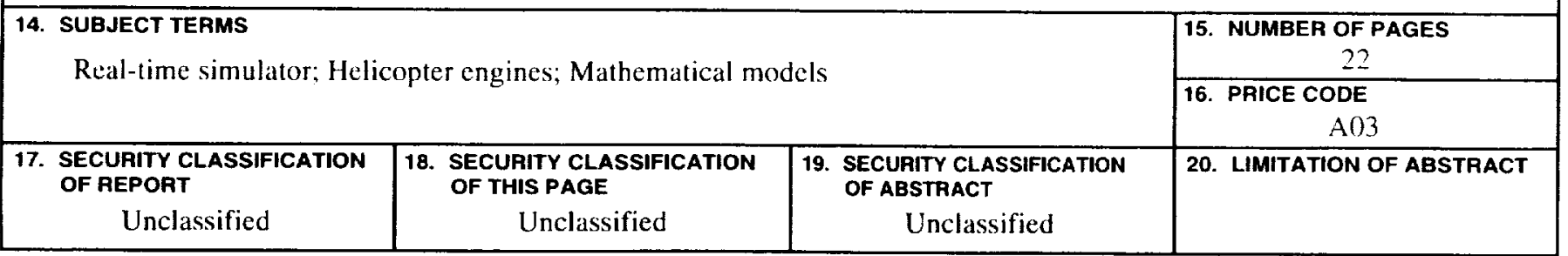


National Aeronautics and

Space Administration

Lewis Research Center

Cleveland, Ohio 44135

Orficial Business

Penaliy for Private Use $\mathbf{\$ 3 0 0}$
FOURTH CLASS MAIL

||||

ADDRESS CORRECTION REQUESTED

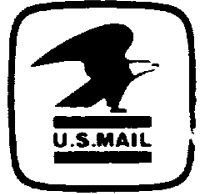

Powtage and Fees om

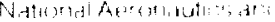

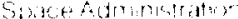

Nain 451 


\section{-}

. 